\title{
Cross-Sectional Imaging in Comparative Vertebrate Morphology - The Intracranial Joint
of the Coelacanth Latimeria chalumnae
}

\author{
Peter Johnston \\ University of Auckland \\ New Zealand
}

\section{Introduction}

Vertebrate morphology, including developmental anatomy, has depended on dissection since anatomical study first began, and on microscopy since the 19th century, in particular since the invention of the microtome. These methods have limitations: dissection destroys tissues, and disturbs or destroys three-dimensional relationships. Microscopy is less destructive, in that sections can be preserved for periods of time, but cutting serial sections, as often used in developmental anatomy, is time-consuming, sections are easily lost in processing, and distortion can be a problem. Three-dimensional (3D) reconstruction for interpretation and demonstration of results was done with manual drawing techniques or physical reconstruction with sequential wax plates, but now can be done with image reconstruction software. Microscopy findings still need to be photographed, aligned and segmented - the tissues of interest identified and marked out on 2D slices - before a result can be obtained, all of which is still relatively labour-intensive.

Functional morphology became accessible with the invention of the motion-picture camera, and cinefluoroscopy with implanted radiological markers has provided many explanations. These traditional techniques have been supplemented in recent years by cross-sectional imaging and advanced techniques that depend on this imaging. CT (computed tomography) and MRI (magnetic resonance imaging) are best known as medical imaging technologies, but have a range of applications in morphology. Newer and more accurate techniques of imaging, real-time imaging for functional study and methods of image reconstruction are revolutionizing vertebrate morphology, bringing 3D information in a non-destructive manner. Rare museum specimens are often not made available for dissection, and these may be important taxa for biological and phylogenetic reasons; imaging techniques have an important application here.

This chapter will review a number of new imaging techniques used in comparative morphology, with examples of recent applications, and will present original research demonstrating a number of these techniques to investigate a morphological mystery, the intracranial joint of the coelacanth Latimeria chalumnae. 


\section{Imaging techniques in comparative morphology}

\subsection{MicroCT}

MicroCT systems are now available at a size and cost suitable for laboratory equipment, with resolution to several microns. This is much more accessible than use of CT scanners at medical facilities, which are typically committed for medical use during office hours. The ability to produce 3D images of small structures replaces laborious and less accurate histological methods. Rieppel et al. (2009) used microCT to examine the skull of the anomalepidid (blindsnake) Liotyphlops albirostris, and were able to resolve a number of issues in the anatomy of the very small skulls of this snake. Preparation of skulls by the usual methods including digestion by enzymes and cleaning by insects may not give satisfactory results in small vertebrates, as the details are difficult to record, and the individual skull bones tend to disarticulate, making it impossible to study the relationships of the bones to the function of the whole skull. Rieppel et al (2009) have been able to make important functional deductions about adaptation to burrowing, and to compare these with another group of blindsnakes, typhlopids, which adapted the skull to a burrowing lifestyle with different morphological details but a similar result.

\subsection{CT examination of fossils}

Radiological examination is valuable for investigating internal cavities and structures in fossilized bones, and for preserving 3D relations and detail for both bones and soft tissues. Some fossils cannot be fully prepared from their rock matrix for fear of damage, and radiological examination can be the only way that details can be examined. Sutton (2008) gives an overview of methods available. CT examination depends mainly on differences in absorption of radiation by the fossil material and the enclosing matrix, although techniques using phase-contrast, which enhances detection of boundaries, are also showing promise.

Gardner et al. (2010) studied skull of the important Permian reptile Youngina with highresolution CT scanning, enabling details of the braincase to emerge for the first time. This taxon is of great importance in the modern reptile evolutionary tree, being close to the stem leading to turtles, and the diapsid groups Archosauria (crocodiles, birds) and Lepidosauria (lizards, snakes, tuatara). The relationships among these modern groups remains uncertain: turtles were traditionally thought to retain their closed-in skull as a primitive feature, but recent evidence points to turtles as diapsid reptiles or even modified lepidosaurs. A number of hypotheses are current. Comparison of Youngina with these modern groups may help to give clearer answers.

\subsection{MicroMRI}

MicroMRI offers better soft tissue definition than microCT, and the output is based on the water content of the different tissues. Ruffins et al. (2007) set out the basis for an atlas of quail embryology with microMRI, achieving good images with resolution to 30 microns. These authors emphasize the ease of preparation of the sample tissue, absence of distortion from processing and ability to re-image the same embryo at a later stage as key advantages of this method. Real-time imaging of cardiac function in animals as small as mice has been achieved (Ross et al., 2002) and this offers considerable scope for investigation of reptiles with different cardiac morphologies. Disadvantages of microMRI are cost and access to suitable MR scanning facilities. 


\subsection{Synchrotron CT}

Synchrotron CT imaging is a particularly exciting development, and a review of some of the applications of this technique is given by Westneat et al. (2008). Synchrotron radiation is produced from high-speed electrons constrained in a circular path, and the resulting X-ray beam is of high energy and narrow band-width ("monochromatic"). The latter feature enables the beam to be focussed, like a beam of light by an optical lens, and phase-contrast techniques are applied to enhance interfaces and edges. Resolution to $30 \mathrm{~nm}$ has been achieved (see references in Westneat et al., 2008). The high photon flux used in this technique allows much faster acquisition times than with conventional radiation sources, and this enables real-time imaging of functions such as respiration and feeding in small invertebrates, which have previously not been amenable to observation. Imaging of soft tissues in 3D is also possible in fossils. Kleinteich et al. (2008) used synchrotron CT to define muscle fibre directions and thus the mechanical implications of muscle placement in caecilian amphibians. Much new data will emerge from this technology, but at present synchrotrons suitable for this purpose are only found in a few sites in the world, and access is thus limited.

\subsection{Tissue contrast in preserved specimens}

Another promising development for comparative morphology is the use of chemical agents for soft tissue contrast in preserved material. Metscher (2009) reviewed data on contrast agents for CT, and gave a variety of examples from original research. Iodine and phosphotungstic acid preparations can give good results, with much better soft tissue definition than microCT without these agents. Jeffery et al. (2011) investigated different protocols for iodine absorption contrast and showed muscle fibre definition in highresolution microCT. Schmidt et al. (2010) used phosphotungstic acid contrast to demonstrate 3D muscle location in normal and genetically modified anuran larvae.

\subsection{D prototyping}

The manufacture of physical models from 3D data derived from cross-sectional imaging is an example of 3D prototyping or 3D printing. Most of the systems available progressively build up a model in slices from image data, using thermoplastic materials. In morphology this method is particularly useful where possible movements between skeletal elements need to be defined. No doubt it will soon be possible to do this on computers with specific software, but for the present, this is a useful way to investigate the range of movement possible movement at joints. For example, Kleinteich et al. (2008) made a physical model of the jaw articulation in caecilian to help understand the movement of the jaw suspension (quadrate bone) on the skull and the musculature associated with this. The result of this was that the mandibular element of the joint enclosed the quadrate element to resist dislocation; this in turn permits a degree of mobility of the quadrate on the braincase. 3D prototyping has until now been an expensive technology, but desk-top systems are now available and the technique is likely to be applied more widely.

\subsection{Movement analysis}

3D data sets derived from cross-sectional imaging can be used in combination with animation software, which allows joints to be defined and their ranges of motions specified. Kargo and Rome (2002) used this method to define activity of hindlimb muscles involved in 
frog jumping, using the software SIMM (Musculographics Inc.), which allows muscle vectors to be applied to the skeleton and the results displayed. Gatesy et al. (2010) have used what they call "scientific rotoscoping" to build animations of skeletal motion modelled on movie sequences of real animals. In their study, skeletal data sets are acquired with CT or optical tomography, reconstructed into a 3D model, and animated with the 3D modelling software Maya (Autodesk) to correspond with live motion data. In a simpler system, Johnston (2010) used 3D coordinates of muscle origins and insertions to define vectors of muscle force acting on the basipterygoid joint in the tuatara Sphenodon. These studies are examples of new functional approaches that may yield important functional information on the skeleton, and may become useful in a phylogenetic context.

\subsection{Methods of reconstruction}

A number of softwares are available commercially and as freeware for reconstructing 3D surfaces and volumes from series of 2D slices. Images of the whole object scanned can be produced by volume rendering, but 3D reconstructions of individual structures or organs within the subject require identification ("segmentation") of these structures. This can be done in some cases with threshold methods, where a particular colour or grey-scale value can be selected and added to the slices, but often segmentation must be done manually, by drawing onto the 2D images. When this is complete, the software creates surfaces corresponding to the margins of the defined areas by adding a triangular mesh. Manual segmentation can be slow work and requires knowledge of what structures are to be expected in the subject. A useful guide to basic functions of three popular programs Amira (Visage Imaging), Osirix (Antione Rosset and Osman Ratib) and Voxx (Indiana University School of Medicine) is given by Corfield et al. (2008). Volumes can be calculated with these methods, and the surfaces generated can be used as a basis of 3D prototyping.

\subsection{Image libraries}

Libraries of cross-sectional images are maintained for access by researchers. The two largest such collections are Digimorph - the University of Texas Digital Morphology Group, http://digimorph.org, and the Digital Fish Library - University of California, San Diego, http://digitalfishlibrary.org. Digimorph offers a wide range of taxa in CT scan data, generally in sections in axial, horizontal and sagittal planes, cutaway movie sequences in the same planes, and roll movies of the whole subject. The Digital Fish Library comprises many fish from all groups in 3 planes of MRI. Both have full data on each specimen scanned. Images can be downloaded from the websites or provided on request for specific projects, both as movie animations and as the original voxel data. The voxel data is ideal for reconstruction work, but involves large files. The movie sequences are valuable for quick reference, and if needed for reconstruction can be turned into a series of aligned 2D images with software such as ImageJ (National Institutes of Health). With practice, the researcher can build up mental reconstructions by scrolling back and forth through 2D sequences. As $3 \mathrm{D}$ imaging progressively becomes a more important part of comparative morphology, these are essential resources for the vertebrate researcher. Smaller archives with specialist themes include those of Witmer (n.d.), Motani (n.d.), and the Computerized Scanning and Imaging Facility of Woods Hole Oceanographic Institute (n.d.). Access to and archiving of this increasing body of data is discussed by Ziegler et al. (2010) and Rowe and Frank (2011), who argue for a model such as the GenBank system for archiving of genetic sequence data. 


\section{The intracranial joint of Latimeria chalumnae}

\subsection{The living coelacanth, a relic of a flourishing lineage}

Coelacanths were once a widespread group of sarcopterygian ("fleshy-finned") fishes, which were thought to have become extinct about 80 million years ago, until the finding in 1938 of an unusual fish in a trawler's catch in East London, South Africa, by Marjorie Courtenay-Latimer, a local museum curator. This was examined by the South African ichthyologist J. L. B. Smith and recognized as a coelacanth on the basis of its characteristic external shape, which has been conserved in coelacanths over 350 million years. The catch was said to have been trawled off the mouth of the Chalumna river, hence the name Latimeria chalumnae. Coelacanth means "hollow spines", referring to the hollow fin rays supporting the tail. In addition to their fleshy fins, which resemble short legs with terminal fins (as opposed to ray fins of teleost lineages), coelacanths present a number of other anatomical features: a double lower jaw articulation, the caudal of which is formed by hyoid arch elements articulating with the mandible; absence of vertebrae, with the notochord forming the axial structural element; ventral position of the kidney in Latimeria, a situation unknown in other vertebrates; a rostral sensory organ, presumed to be electroreceptive; a transverse joint across the middle of the skull, and a longitudinal muscle along the base of the skull, the basicranial muscle, in a position to ventrally flex the skull at this joint. The most important study of the anatomy of Latimeria has been the large general survey of Millot and Anthony and colleagues (Millot and Anthony, 1958; 1965; Millot et al., 1978) and colleagues. A variety of papers on specific anatomy have also been published, and are listed by Bruton et al. (1991). A comprehensive account of coelacanth osteology, together with general aspects of Latimeria biology, was given by Forey (1998).

Since the original discovery of Latimeria chalumnae, over 300 specimens have been taken from fishermen along the east coast of southern Africa, mostly in the Comores islands, which lie between Madagascar and Mozambique. Latimeria lives at depths not generally amenable to SCUBA diving, and observations in the wild have been few, and mainly conducted by submersible craft. Recently, detailed close-up photographs of Latimeria in natural habitat have been obtained at about 100 metres at Sodana Bay, South Africa (Butler and Ballesta, 2011). In 1997, living coelacanths were discovered in North Sulawesi, Indonesia, again being recognised by chance in a fisherman's catch by a biologist. Genetic testing suggests this is a different species, and it is now named Latimeria menadoensis.

\subsection{The problem: The intracranial joint}

The intracranial joint and its associated basicranial muscle are known in another group of sarcopterygian fossil fish, the rhipidistians, which are closer to the stem on the evolutionary tree that leads to tetrapods. A simplified tree after Yu et al. (2010) showing the relationships of gnathostomes (vertebrates with jaws) is given in Fig. 1. The function of the intracranial joint had never been convincingly explained despite its being a major feature of the sarcopterygian skull, and it was hoped that analysis of the Latimeria joint would lead to an understanding of its place in the predecessors of tetrapods (Forey, 1998). However, there has been debate about whether the joint is the same structure in coelacanths and rhipidistians; current opinion favours homology of this structure in these groups (Janvier, 1996). A variety of interpretations of the Latimeria intracranial joint have been advanced. The inability to sustain captive Latimeria has meant that direct observation has been very limited, and confined to manipulation of a few recently dead specimens. A number of notable 


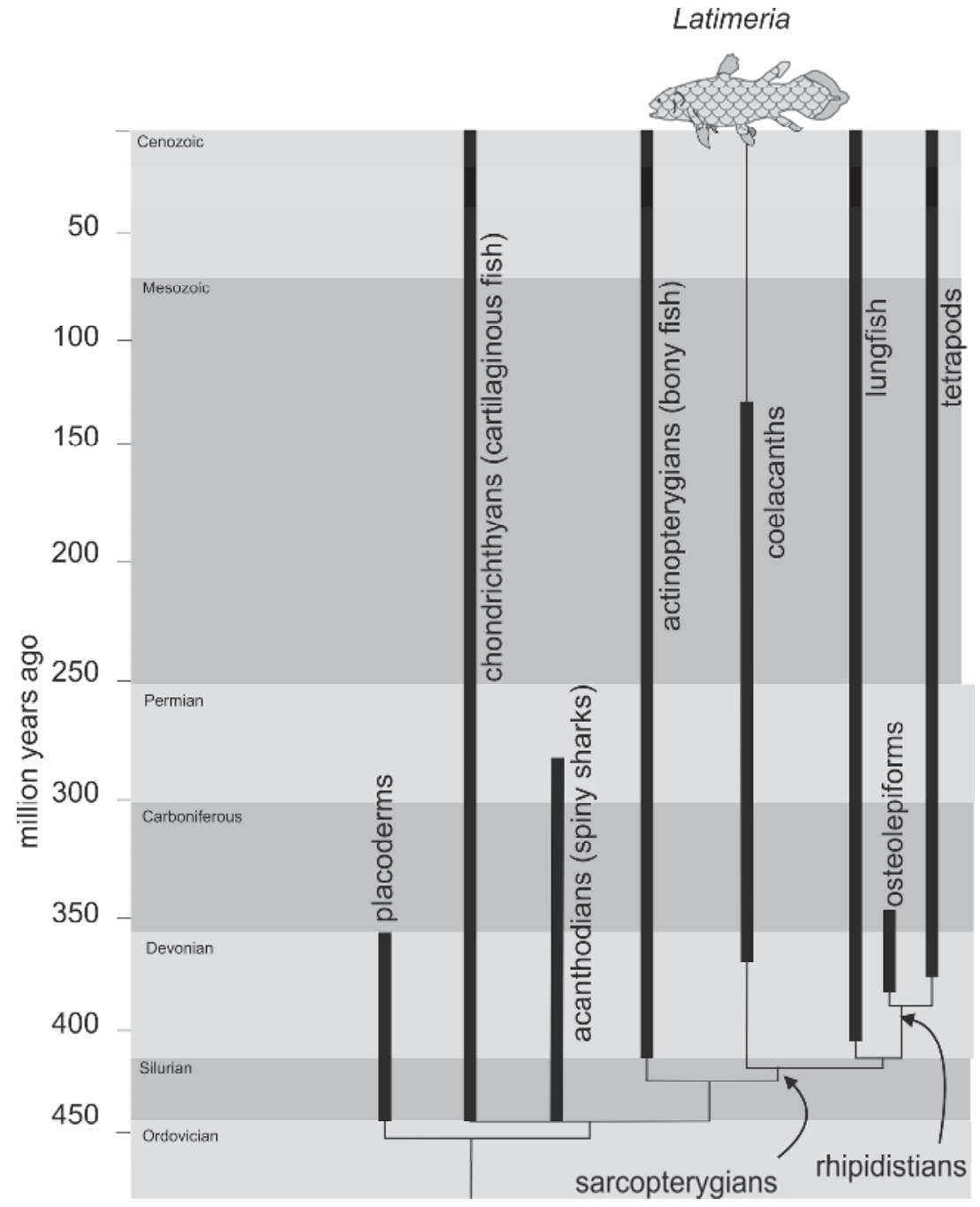

Fig. 1. Cladogram showing relationship of coelacanths to other gnathostomes.

ichthyologists and palaeontologists (and one distinguished ornithologist) have published on this structure. A summary of these studies is given below. The other important feature to be discussed in the sarcopterygian skull is the notochord. This was the primitive longitudinal support of the body before the evolution of the vertebral column, which is a series of ossifications around the notochord. The notochord is a prominent feature in developing vertebrates, and regresses to various extents in most taxa. The intracranial portion of the notochord regresses completely in all extant taxa except Latimeria. Fossil sarcopterygians also retained the intracranial notochord. In the embryo, the notochord has an important organizing function in development (Stemple, 2005). In the adult, where it is retained, it has a structural role as a hydraulic rod, having a viscous fluid-filled centre and a tough fibrous 
covering. The intracranial joint is situated between the ethmosphenoid and oto-occipital sections of the braincase; there is a dorsal articulation in the skull roof bones, and a ventral articulation at the base of the skull, immediately dorsal to the notochord. The location of the joint is shown in its location in the skull in Figs. $2 a$ and $2 b$, and its components are labelled in Fig. 2c.

\subsubsection{Latimeria cranial anatomy: Publications up to $\mathbf{1 9 8 0}$}

The work of Jacques Millot and Jacques Anthony $(1958,1965,1978)$ and colleagues remain standard accounts of the morphology, based on dissection of a number of specimens. These authors considered that very little movement was possible at the joint in their first book, but by the time of the 1978 volume had been influenced by the mechanical theories of Keith Thomson (Thompson, 1966) and others. Thomson (1966; 1967) studied the intracranial joint in both rhipidistians and coelacanths. He reported that dorsal flexion at the joint in Latimeria to $20-30^{\circ}$ is possible (Fig. $2 \mathrm{~d}$ ), around the fulcrum of the dorsal part of the joint in the skull roof, and related this to movements of the hyoid cartilages, jaw opening, and widening of the gape by dorsal flexion of the snout. These inferences were generalized to rhipidistians.
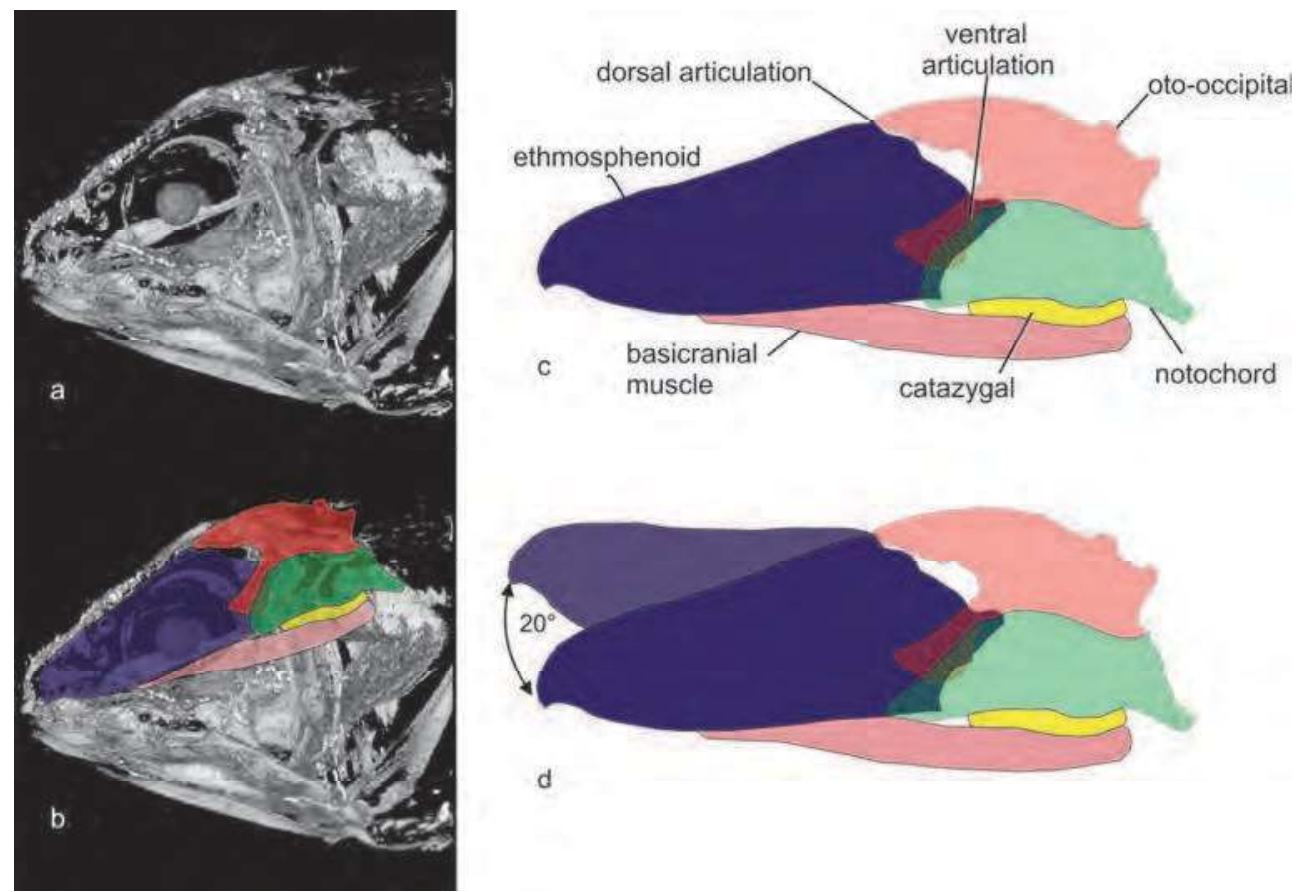

Fig. 2. a, b: Latimeria skull with braincase superimposed. c: median sagittal section of braincase with intracranial articulations and notochord. $\mathrm{d}$ : dorsal flexion of rostral braincase, as in previous hypotheses.

R. McNeil Alexander (1973) presented a rather similar analysis in Latimeria, having examined an unfixed specimen, and concluded that dorsal flexion to perhaps $15^{\circ}$ is possible. 
Other interpretations also included dorsal flexion at the dorsal articulation, to widen the gape (Adamicka and Ahnelt, 1976; Cracraft, 1968)

\subsubsection{Latimeria cranial anatomy: After 1980}

George Lauder (1980) also accepted dorsal flexion, and proposed a more detailed model involving initiation of jaw opening by dorsal flexion of the occiput on the body by the epaxial muscles and retraction of the hyoid apparatus by the sternohyoideus muscle, causing rostral displacement of the main jaw articulation, such that the axis of dorsal force on the palatoquadrate lay rostral to the intracranial joint, with consequent dorsal flexion. This dorsal flexion is an integral part of the jaw-opening mechanism in Lauder's plan. Erik Jarvik (1980) summarized many years' experience with rhipidistians and considered that little translatory or angular movement was possible in any coelacanth or rhipidistian. Edward Hitchcock (1995) accepted dorsal flexion in both coelacanths and rhipidistians.

Philippe Janvier's (1996) book offers a detailed survey of early vertebrates and discusses the existence or possibility of an intracranial joint in all lineages. He considered the Latimeria skull to permit very limited movement on morphological grounds. Peter Bernstein (2002) examined the morphology of the intracranial joint in a serially sectioned juvenile Latimeria head. His principal finding was that in the ventral part of the joint, the ethmosphenoid component articulates closely as longitudinal rails within grooves in the oto-occipital part of the joint. He concluded that this arrangement allows longitudinal, plunger-type mobility but not dorso-ventral flexion.

Kanyukin (2009) advanced a more complex proposal for movement of the hyoid apparatus than that of Lauder (1980), again requiring dorsal flexion of the ethmosphenoid. The inference of recent discussions (Bernstein, 2002; Forey, 1998; Janvier, 1996) is similar to that of Jarvik (1980): even if Latimeria does have dorsal flexion of the joint, this is not relevant to rhipidistians or even to other coelacanths, in which the morphology would not permit this. Latimeria is a derived (end of an evolutionary branch) rather than plesiomorphic (showing generalized features) coelacanth.

The basicranial muscle has given rise to interesting discussion about its innervation and homologies; the conclusion of Bemis and Northcutt (1991) that the muscle is supplied by the sixth cranial nerve is the most robust, and the homology of this muscle with the m. retractor bulbi of tetrapods has thus been considered.

\subsection{Statement of the problem}

The function of the intracranial joint in Latimeria remains unclear, and it is also uncertain whether an understanding of the coelacanth joint can be generalized to rhipidistians. A major feature of the skull in the forerunners of tetrapods is still a mystery.

\section{Original research}

\subsection{Aims}

The aims of the current study are to reconstruct the ethmosphenoid and oto-occipital sections of the braincase from CT and MRI scan images, build physical models with 3D prototyping to establish what mobility is possible at the intracranial joint, and discuss this mobility in the context of sarcopterygian evolution. 


\subsection{Methods}

Most of the braincase in Latimeria is cartilaginous, and not visible on the CT scans available, thus MRI scans are needed in addition. The dermal skull roof bones are, however, well shown with CT, as is the palatal bone assembly, which is not reconstructed here. These bony structures are not well seen on MRI, and a variable degree of signal loss is present in and around the bones; the combination of CT and MRI is thus necessary. The identification of individual structures is still a complex process, and requires correlation with published anatomical resources on Latimeria.

\subsubsection{Image sources}

CT scan images were provided by the University of Texas Digital Morphology Group, from the Digimorph archive; specimen: American Museum of Natural History AMNH 32949, an embryo. MRI scan images were provided by the Digital Fish Library, University of California, San Diego; specimen: Marine Vertebrate Collection, Scripps Oceanological Institute, SIO 75-347, a 950mm long adult. Cross-sectional images drawn from macroscopic slices by Millot and Anthony (1958) and from microscopic sections by Bernstein (2002) were used to help identify structures in the scans.

\subsubsection{Segmentation and reconstruction}

DICOM image series were viewed with ImageJ (NIH). QuickTime (Apple Inc.) movie animations were converted to serial images with ImageJ. Segmentation and reconstruction were done with Amira 5.2.1 (Visage Imaging), tracing structures onto the MR images with frequent reference to CT data. Although Amira has a facility for registering two sets of data, this was not possibly here as the scans were of different specimens. The ethmosphenoid and oto-occipital blocks were outlined, and also the cranial part of the notochord. The anazygal, which bridges between the oto-occipital blocks dorsal to the notochord, has been included with the oto-occipital for the purposes of 3D prototyping. Other cranial structures including the hyoid arch elements and palatoquadrate were also segmented but not included in the present analysis. Fig. 3 shows equivalent CT and MRI slices, and the segmentation window in Amira 5.2.1.

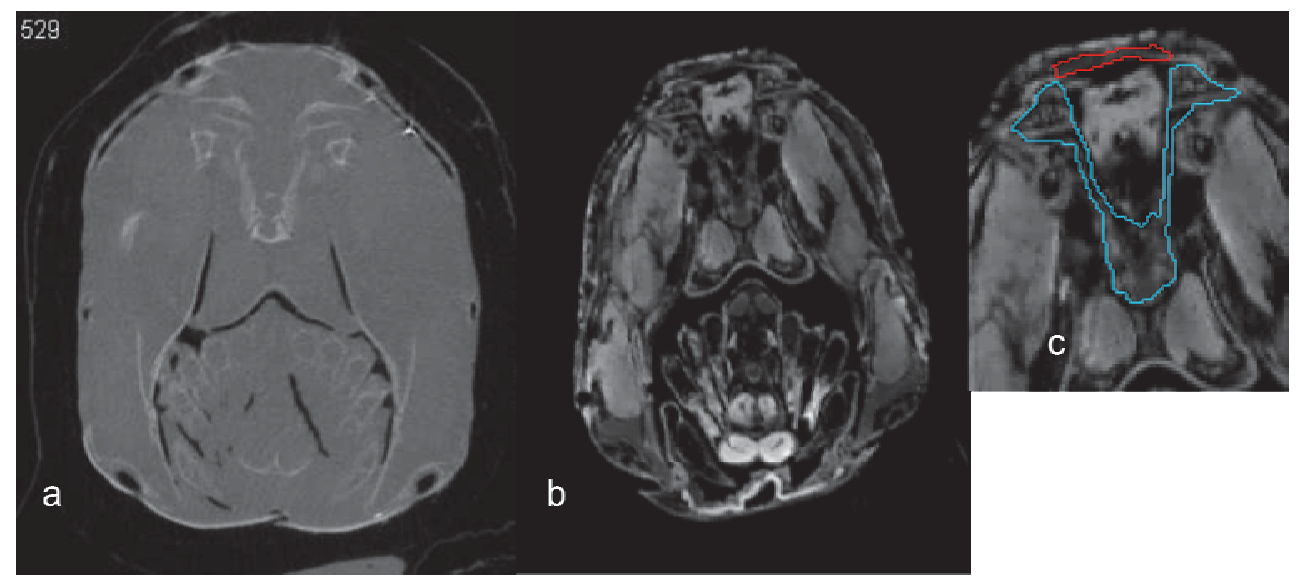

Fig. 3. a: CT axial (coronal) slice; b: equivalent MRI slice; c: segmentation window in Amira 5.2.1, ethmosphenoid in blue, oto-occipital in red. 


\subsubsection{D prototyping}

The ethmosphenoid and oto-occipital blocks were generated as surfaces in Amira, and saved as .stl files for 3D prototyping, which was done with a fused deposition modelling (FDM) system, using ABS (acrylonitrile butadiene styrene) plastic.

\subsection{Results}

The reconstructed ethmosphenoid and oto-occipital blocks are shown in Fig. 4a. The dorsal part of the intracranial joint is a simple butt joint, as described by all previous authors. The ventral joint has the rails-within-grooves morphology described by Bernstein (2002), with an angle of $40^{\circ}$ to the horizontal. The ethmosphenoid "rails" are the condyles of Millot and Anthony (1958) (Fig. 4c), and diverge laterally within the oto-occipital components to form a locking mechanism resisting longitudinal displacement (Fig. 3e). When the two sections are articulated, they lock neatly together, and only a $5^{\circ}$ angulation ventrally is possible from the "neutral" position in which both specimens were scanned (Fig. 4b). This small rotation takes place around an axis between the dorsal and ventral intracranial joints. No dorsal flexion of the ethmosphenoid component is possible at all.

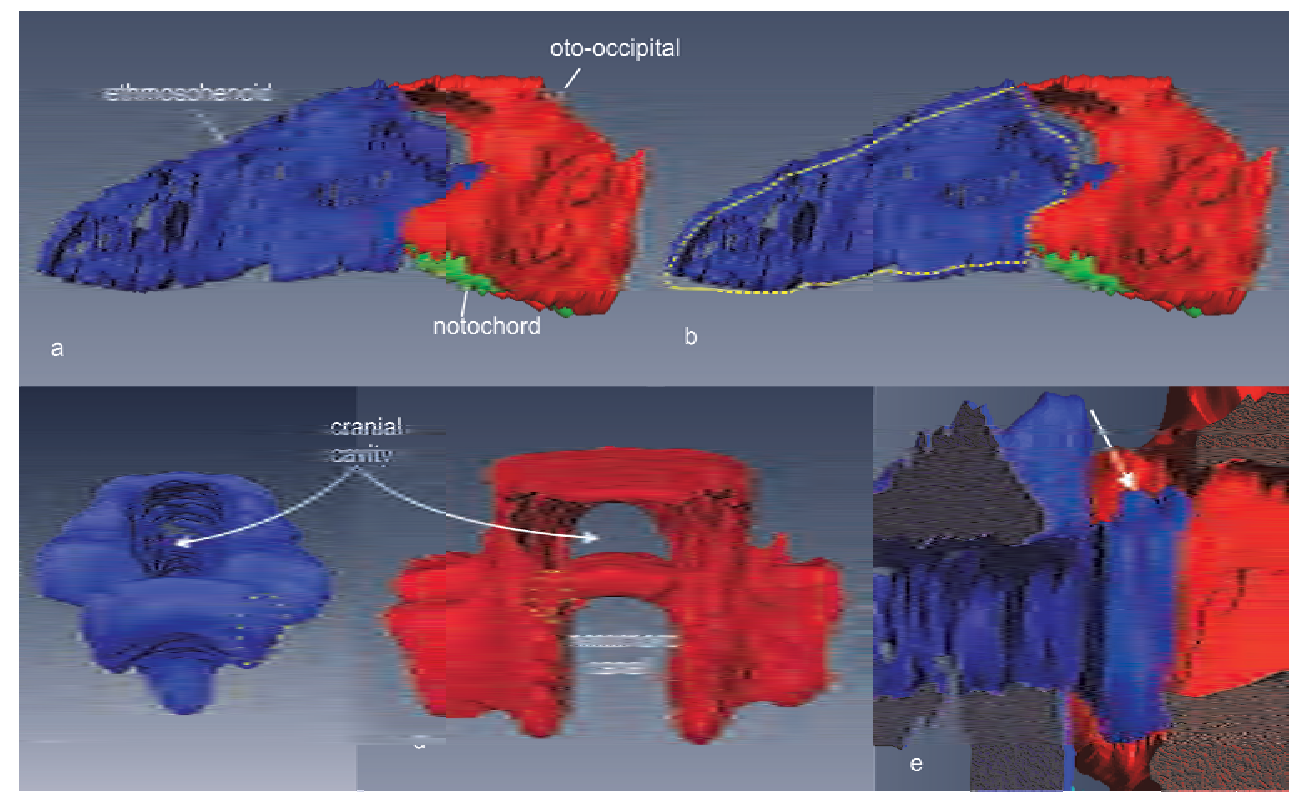

Fig. 4. Reconstructions of braincase and notochord, left lateral view; b: the limit of mobility at the intracranial joint is indicated by the dotted line; c: caudal view of ethmosphenoid, the articular condyle is outlined on the right side; d: rostral view of oto-occipital, socket for the condyle outlined; e: dorsal view of intracranial joint after removal of the roof of the braincase, the arrow points to the locking of the components.

\subsection{Interpretation}

These findings accord with those of Millot and Anthony (1958) and with the interpretation of Jarvik (1980). The analyses involving dorsal flexion at the intracranial joint (sections 3.2.2 
and 3.2.3) are not compatible with the morphology revealed here. The jaw-opening mechanism suggested by Lauder (1980) is otherwise convincing however, and remains the best explanation of the hyoid apparatus and double jaw articulation of the coelacanth. The minor amount of movement allowed by this result provides no easy explanation for the basicranial muscle, which is relatively large in Latimeria. The studies involving manipulation of a recently dead or thawed specimen (Thomson, 1966 and Alexander, 1973) have not used radiological confirmation of movement at the joint, and the dorsal flexion observed must have been movement of the whole skull on the notochord at the occiput.

\section{Discussion}

\subsection{The intracranial joint of sarcopterygians}

The intracranial joint of adult sarcopterygians, excluding lungfish, represents a major difference from the fused sphenoid and otic regions of modern chondrichthyans (cartilaginous fish), actinopterygians (ray-finned bony fish) and tetrapods. The putative ancestors of lungfish also had such a joint: the taxa Youngolepis and Powichthys are Dipnomorpha, on the branches leading to lungfish. These taxa have an intracranial joint that is identifiable but either very narrow or closed, and retain an incomplete intracranial notochord. In the actinopterygian lineage, in quite a similar morphology, the taxa Mimia and Kansasiella had the notochord still present within the base of the skull but regressed caudally from the intracranial joint, which was narrow or closed (Janvier, 1996). The incompletely closed ventral part of the joint appears to be represented in later actinopterygians by the ventral cranial fissure; there has been some debate about this, but this interpretation offers the best explanation (Janvier, 1996).

In the absence of an obvious function in jaw action of this joint in Latimeria, it is appropriate to consider possible functions of the joint applicable to all sarcopterygians. The presence of the intracranial notochord is closely linked with the existence of an intracranial joint (Janvier, 1996), and the explanation which has been assumed, and not examined in detail, is that the notochord is needed to provide flexibility to the base of the skull so that the joint can operate. The basicranial muscle in this model is the ventral flexor of the joint.

\subsection{The primary role of the intracranial notochord}

I would like to turn this association around, and suggest that the retention of the intracranial notochord is the primary evolutionary event, and that the intracranial joint exists to deal with pressure and length changes in the notochord. No research on the physical properties of the Latimeria notochord has been published. The closest similarity to the Latimeria notochord in a living animal is the sturgeon, which has an unconstricted extracranial notochord as its axial support. Studies on the sturgeon notochord (Long, 1995) have examined its flexibility and contribution to an undulating swimming motion, but not the effects of movement on the notochord itself. Koehl et al. (2000) have investigated the physical properties of the Xenopus tadpole notochord with models of a fibre-wound hydraulic skeleton. It was found that bending and straightening of the model resulted in lengthening or shortening, depending on the angle at which the fibres (collagen in life) are wound onto the viscous core. A model of the Latimeria 
notochord with an appropriate viscous core and fibrous coating would be needed to advance this suggestion, but from present knowledge it is reasonable to conclude that the notochord in Latimeria may be subject to changes in length and pressure with swimming motion.

The intracranial joint and basicranial muscle could thus be seen as a shock-absorbing mechanism, to deal with these changes in the intracranial notochord. The skull elements, notochord and basicranial muscle are thus in a dynamic balance. The mechanical opposition of the notochord and the basicranial muscle has been recognised by Millot and Anthony (1958) and subsequent authors, but in the context of the intracranial joint being the primary functional element, rather than the notochord.

Key taxa for evaluating this hypothesis further in sarcopterygian evolution are those in which the intracranial joint is closed (or very narrow) and the intracranial notochord has not regressed to the back of the skull. Such taxa are the dipnomorph Youngolepis (Chang, 2004), as mentioned above, and the tetrapodomorphs Acanthostega gunnari (Clack, 1998) and Mandageria fairfaxi (Johanson et al., 2003). Correlation with the morphology of the postcranial axial skeleton will also be important, both in these transitional forms and in sarcopterygians as a group.

\section{Conclusions}

\subsection{Imaging techniques}

The various recent advances based on cross-sectional imaging set out in section 2 above are new tools for the morphologist, and depend on the ability of computer systems to record, calculate and display 3D data. With the availability of high resolution CT and MRI, and realtime display with synchrotron imaging, these tools are now applicable to invertebrate as well as vertebrate study. Hopefully costs of some these relatively expensive techniques will come down in time, and access to synchrotron imaging or a similar high-energy radiation source will become wider.

\subsection{The intracranial joint of Latimeria}

The original research on the intracranial joint presented here demonstrates the use of some the tools described in section 2: CT and MRI scanning, 3D reconstruction and 3D prototyping. These methods have enabled new functional anatomical data to be applied to the unresolved problem of the sarcopterygian intracranial joint. It is very unlikely that museum specimen of Latimeria would be made available for such a study, emphasizing the value of these non-destructive techniques.

\subsubsection{Future research}

Further work can be done with the data described here, adding the segmentation of the hyoid elements, palatoquadrate and mandible to the reconstruction, and then adding mobile joints in an animation software, probably with the help of more 3D prototyping. Lauder's (1980) scheme for the function of the hyoid apparatus, mandible and skull can then be revised in light of the data on intracranial joint mobility described above. Building a physical model of the Latimeria notochord, with an accurately copied fibre-wound external sheath and viscous interior, would also elucidate the issues raised here. 


\subsubsection{The problem - reframing the question}

In an evolutionary context, the hypothesis offered here, that the sarcopterygian intracranial joint exists to deal with mechanical effects of notochord bending, can be developed by close examination of taxa with transitional states of reduction of the joint. If this hypothesis is upheld, the major question then changes from "what is the function of the intracranial joint?" to "why does the intracranial notochord persist in sarcopterygian lineages?". The regression of the notochord from the base of the skull in the rhipidistian-tetrapod transition is not difficult to understand: the development of the occipito-vertebral joint, separation of the dorsal skull form the shoulder girdle and regression of the notochord all increase mobility of the head on the body as an adaptation to life on land. On the other hand, the retention of the notochord in the adult sarcopterygian skull contrasts with its loss or reduction in all other cartilaginous and bony fish, and no developmental or functional explanation has yet been suggested.

\section{Acknowledgements}

For the CT scan images I am grateful to Timothy Rowe and Jessie Maisano, University of Texas Digital Morphology Group, and for the MRI scans, Larry Frank and Rachel Berquist of the Digital Fish Library, University of California, San Diego. The Digital Fish Library project is funded by NSF grant number: DBI-0446389. I thank Brett Cowan for technical discussion on MRI, and Andrew Kersley for information on 3D prototyping. I am grateful to Casey Holliday for pointing out literature on contrast use for CT.

\section{References}

Adamicka, P. \& Ahnelt, H. (1976). Beiträge zur funktionellen Analys und zur Morphologie des Kopfes von Latimeria chalumnae Smith. Annal des (KK) Naturhistorischen (Hof) Museums, Wien 80:251-271.

Alexander, R.M. (1973). Jaw mechanisms of the coelacanth Latimeria. Copeia 1973:156-158. ISSN 0045-8511

Bemis, W.E. \& Northcutt, R.G. (1991). Innervation of the basicranial muscle in Latimeria chalumnae. Environmental Biology of Fishes 32:147-157. ISSN 0378-1909

Bernstein, P. (2002). Die evolutive Transformation der Oticalregion der Sarcopterygii beim Übergang vom Wasser- zum Landleben. Thesis: Tübingen, Eberhard-KarlsUniversität. $179 \mathrm{p}$.

Bruton, M.N., Coutouvidis, S.E. \& Pote, J. (1991). Bibliography of the living coelacanth Latimeria chalumnae with comments on publication trends. Environmental Biology of Fishes 32:403-433. ISSN 0378-1909

Butler, C. \& Ballesta, L. (2011). Ancient swimmers. National Geographic 219(3):86-93.

Chang, M-M. (2004). Synapomorphies and scenarios - more characters of Youngolepis betraying its affinity to the Dipnoi. In: Arratia G, Wilson MVH, Cloutier R, editors. Recent advances in the origin and early radiation of vertebrates. München: Verlag Dr Freidrich Pfeil. p 665-686. ISBN 3899372052X

Clack, J.A. (1998). The neurocranium of Acanthostega gunnari Jarvik and and the evolution of the otic region in tetrapods. Zoological Journal of the Linnean Society 122:61-97. ISSN 0024-4082 
Corfield, J.R., Wild, J.M., Cowan, B.R., Parsons, S. \& Kubke, M.F. (2008). MRI of postmortem specimens of endangered species for comparative brain anatomy. Nature Protocols 3:597-605. ISSN 1750-2799

Cracraft, J. (1968). Functional morphology and adaptive significance of cranial kinesis in Latimeria chalumnae (Coelacanthini). American Zoologist 8:354. ISSN 0003-1569

Forey, P.L. (1998). History of the Coelacanth Fishes. London: Chapman and Hall. 419 p. ISBN 0412784807

Gardner, N.M., Holliday, C.M. \& O'Keefe, F.R. (2010). The braincase of Youngina capensis (Reptilia: Diapsida): new insights from high-resolution CT scanning of the holotype. Palaeontologia Electronica. p 16. ISSN 1094-8074

Gatesy, S.M., Baier, D.B., Jenkins, F.A. \& Dial, K.P. (2010). Scientific rotoscoping: a morphology-based method of 3-D motion analysis and visualization. Journal of Experimental Zoology 313A:244-261. ISSN 1548-8969

Hitchcock, E.C. (1995). A functional interpretation of the anteriormost vertebrae and skull of Eusthenopteron. Bulletin du Muséum national d'Histoire naturelle, 4ieme séries, section C 17:269-285.

Computerized Scanning and Imaging Facility of the Woods Hole Oceanographic Institute. (n.d.). Accessed April 2011. Available at: http://www.whoi.edu/csi.

Janvier, P. (1996). Early Vertebrates. Oxford: Clarendon Press. 393 p. ISBN 0198540477

Jarvik, E. (1980). Basic structure and evolution of vertebrates. London: Academic Press. 575 p. ISBN 0123808014

Jeffery, N.S., Stephenson, R.S., Gallagher, J.A., Jarvis, J.C. \& Cox, P.G. (2011). Microcomputed tomography with iodine staining resolves the arrangement of muscle fibres. Journal of Biomechanics 44:189-192. ISSN 0021-9290

Johanson, Z., Ahlberg, P. \& Ritchie, A. (2003). The braincase and palate of the tetrapodomorph sarcopterygian Mandageria fairfaxi: morphological variability near the fish-tetrapod transition. Palaeontology 46:271-293. ISSN 0031-0239

Johnston, P. (2010). The constrictor dorsalis musculature and basipterygoid articulation in Sphenodon. Journal of Morphology 271:280-292. ISSN 0362-2525

Kanyukin, A.A. (2009). The role of hyobranchial skeletal elements in the Rhipidistian intracranial kinetic mechanism. Doklady Biological Sciences 428:278-281.

Kargo, W.J. \& Rome, L.C. (2002). Functional morphology of proximal hindlimb muscles in the frog Rana pipiens. Journal of Experimental Biology 205:1987-2004. ISSN 0022-0949

Kleinteich, T., Haas, A. \& Summers, A.P. (2008). Caecilian jaw-closing mechanics: integrating two muscle systems. Journal of the Royal Society Interface 5:1491-1504. ISSN 1742-5662

Koehl, M.A.R., Quillin, K.J. \& Pell, C.A. (2000). Mechanical design of fiber-wound hydraulic skeletons: the stiffening and straightening of embryonic notochords. American Zoologist 40(28-41). ISSN 0003-1569

Lauder, G.V. (1980). The role of the hyoid apparatus in the feeding mechanism of the coelacanth Latimeria chalumnae. Copeia 1980:1-9. ISSN 0045-8511

Long, J.H. (1995). Morphology, mechanics and locomotion: the relation between the notochord and swimming motions in the sturgeon. Environmental Biology of Fishes 44:199-211. ISSN 0378-1909 
Metscher, B.D. (2009). MicroCT for comparative morphology: simple staining methods allow high-contrast 3D imaging of diverse non-mineralised animal tissues. BMC Physiology 9:11. ISSN 1472-6713

Millot, J. \& Anthony, J. (1958). Anatomie de Latimeria chalumnae. Paris: CNRS. 122 p.

Millot, J., \& Anthony, J. (1965). Anatomie de Latimeria chalumnae. II Système nerveux et organes des sens. Paris: C.N.R.S. 131 p.

Millot, J., Anthony, J. \& Robineau D. (1978). Anatomie de Latimeria chalumnae. Paris: CNRS. $198 \mathrm{p}$.

Motani, R. (n.d.) Accessed April 2011. Available at: http://3dmuseum.org.

Rieppel, O., Kley, N.J. \& Maisano J.A. (2009). Morphology of the skull of the white-nosed blindsnake, Liotyphlops albirostris (Soclecophidia: Anomalepididae). Journal of Morphology 270:536-557. ISSN 0362-2525

Ross, A.J., Yang, Z., Berr, S.S., Gilson, W.D., Peterson, W.C., Oshinski, J.N. \& French, B.A. (2002). Serial MRI evaluation of cardiac structure and function in mice after reperfused myocardial infarction. Magnetic Resonance in Medicine 47:1158-1168. ISSN 0740-3194

Rowe, T. \& Frank, L.R. (2011). The disappearing third dimension. Science 331:712-714. ISSN 0036-8075

Ruffins, S.W., Martin, M., Keough, L., Truong, S., Fraser, S.E., Jacobs, R.E. \& Lansford, R. (2007). Digital three-dimensional atlas of quail development using highresolution MRI. TSW Development and Embryology 2:47-53.

Schmidt, J., Schuff, M. \& Olsson, L. (2011). A role for FoxN3 in the development of cranial cartilages and muscles in Xenopus laevis (Amphibia: Anura: Pipidae) with special emphasis on the novel rostral cartilages. Journal of Anatomy : 218: 226-242. ISSN 0021-8782

Stemple, D.L. (2005). Structure and function of the notochord: an essential organ for chordate development. Development 132:2503-2512. ISSN 0950-1991

Sutton, M.D. (2008). Tomographic techniques for the study of exceptionally preserved fossils. Proceedings of the Royal Society B 275:1587-1593. ISSN 0950-1193

Thomson, K.S. (1966). Intracranial mobility in the coelacanth. Science 153:999-1000. ISSN 0036-8075

Thomson, K.S. (1967). Mechanisms of intracranial kinetics in fossil rhipidistian fishes (Crossopterygii) and their relatives. Zoological Journal of the Linnean Society 46:223253. ISSN 0024-4082

Westneat, M.W., Socha, J.J. \& Lee, W-K. (2008). Advances in biological structure, function and physiology using synchrotron X-ray imaging. Annual Review of Physiology 70:119-142. ISSN 0066-4278

Witmer, L. (n.d.) Accessed April 2011. Available at: http://www.oucom.ohiou.edu/dbms-witmer/3D-visualization.htm.

Yu, X., Zhu, M. \& Zhao, W. (2010). The origin and diversification of osteichthyans and sarcopterygians: new Chinese fossil findings advance research in key areas of evolution. Bulletin of the Chinese Academy of Sciences 24(2):71-75. 
Ziegler, A., Ogurreck, M., Steinke, T., Beckmann, F., Prohaska, S. \& Ziegler, A. (2010). Opportunities and challenges for digital morphology. Biology Direct. 5:45. ISSN 1745-6150 


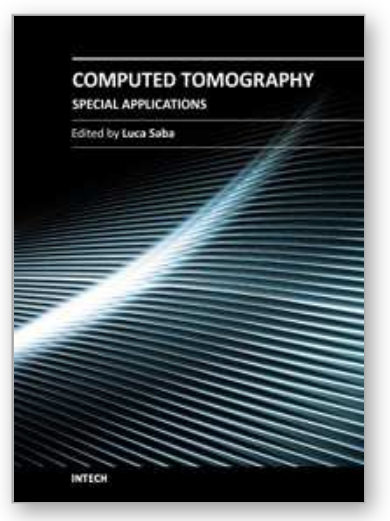

\author{
Computed Tomography - Special Applications \\ Edited by Dr. Luca Saba
}

ISBN 978-953-307-723-9

Hard cover, 318 pages

Publisher InTech

Published online 21, November, 2011

Published in print edition November, 2011

CT has evolved into an indispensable imaging method in clinical routine. The first generation of CT scanners developed in the 1970s and numerous innovations have improved the utility and application field of the CT, such as the introduction of helical systems that allowed the development of the "volumetric CT" concept. Recently interesting technical, anthropomorphic, forensic and archeological as well as paleontological applications of computed tomography have been developed. These applications further strengthen the method as a generic diagnostic tool for non destructive material testing and three dimensional visualization beyond its medical use.

\title{
How to reference
}

In order to correctly reference this scholarly work, feel free to copy and paste the following:

Peter Johnston (2011). Cross-Sectional Imaging in Comparative Vertebrate Morphology - The Intracranial Joint of the Coelacanth Latimeria chalumnae, Computed Tomography - Special Applications, Dr. Luca Saba (Ed.), ISBN: 978-953-307-723-9, InTech, Available from: http://www.intechopen.com/books/computedtomography-special-applications/cross-sectional-imaging-in-comparative-vertebrate-morphology-theintracranial-joint-of-the-coelacant

\section{INTECH}

open science | open minds

\section{InTech Europe}

University Campus STeP Ri

Slavka Krautzeka 83/A

51000 Rijeka, Croatia

Phone: +385 (51) 770447

Fax: +385 (51) 686166

www.intechopen.com

\section{InTech China}

Unit 405, Office Block, Hotel Equatorial Shanghai

No.65, Yan An Road (West), Shanghai, 200040, China 中国上海市延安西路65号上海国际贵都大饭店办公楼 405 单元

Phone: +86-21-62489820

Fax: +86-21-62489821 
(C) 2011 The Author(s). Licensee IntechOpen. This is an open access article distributed under the terms of the Creative Commons Attribution 3.0 License, which permits unrestricted use, distribution, and reproduction in any medium, provided the original work is properly cited. 